\title{
Article \\ Empirical Support for the Pattern of Competitive Exclusion between Insect Parasitic Fungi
}

\author{
Shiqin $\mathrm{Li}^{1,2}$, Wenjuan $\mathrm{Yi}^{1}$, Siyi Chen ${ }^{1,2}$ and Chengshu Wang ${ }^{1,2,3, * \mathbb{D}}$ \\ 1 CAS Center for Excellence in Molecular Plant Sciences, Key Laboratory of Insect Developmental and \\ Evolutionary Biology, Shanghai Institute of Plant Physiology and Ecology, Chinese Academy of Sciences, \\ Shanghai 200032, China; lishq1@shanghaitech.edu.cn (S.L.); 18270821134@163.com (W.Y.); \\ chensy3@shanghaitech.edu.cn (S.C.) \\ 2 School of Life Science and Technology, ShanghaiTech University, Shanghai 201210, China \\ 3 CAS Center for Excellence in Biotic Interactions, University of Chinese Academy of Sciences, \\ Beijing 100049, China \\ * Correspondence: wangcs@sippe.ac.cn; Tel.: +86-21-54924157; Fax: +86-21-54924015
}

Citation: Li, S.; Yi, W.; Chen, S.; Wang, C. Empirical Support for the Pattern of Competitive Exclusion between Insect Parasitic Fungi. J. Fungi 2021, 7, 385. https://doi.org/ $10.3390 /$ jof7050385

Academic Editor: Ivan M. Dubovskiy

Received: 19 April 2021

Accepted: 11 May 2021

Published: 14 May 2021

Publisher's Note: MDPI stays neutral with regard to jurisdictional claims in published maps and institutional affiliations.

Copyright: (C) 2021 by the authors. Licensee MDPI, Basel, Switzerland. This article is an open access article distributed under the terms and conditions of the Creative Commons Attribution (CC BY) license (https:// creativecommons.org/licenses/by/ $4.0 /)$.

\begin{abstract}
Fungal entomopathogens are largely facultative parasites and play an important role in controlling the density of insect populations in nature. A few species of these fungi have been used for biocontrol of insect pests. The pattern of the entomopathogen competition for insect individuals is still elusive. Here, we report the empirical competition for hosts or niches between the inter- and intra-species of the entomopathogens Metarhizium robertsii and Beauveria bassiana. It was found that the synergistic effect of coinfection on virulence increase was not evident, and the insects were largely killed and mycosed by $M$. robertsii independent of its initial co-inoculation dosage and infection order. For example, $>90 \%$ dead insects were mycosed by $M$. robertsii even after immersion in a spore suspension with a mixture ratio of 9:1 for B. bassiana versus $M$. robertsii. The results thus support the pattern of competitive exclusion between insect pathogenic fungi that occurred from outside to inside the insect hosts. Even being inferior to compete for insects, B. bassiana could outcompete M. robertsii during co-culturing in liquid medium. It was also found that the one-sided mycosis of insects occurred during coinfection with different genotypic strains of either fungi. However, parasexual recombination was evident to take place between the compatible strains after coinfection. The data of this study can help explain the phenomena of the exclusive mycosis of insect individuals, but co-occurrence of entomopathogens in the fields, and suggest that the synergistic effect is questionable regarding the mixed use of fungal parasites for insect pest control.
\end{abstract}

Keywords: fungal parasite; insect host; competition; mycosis; coexistence; ecological niches

\section{Introduction}

Fungi are the second most species-rich eukaryotic group after the insects [1,2]. After long-term coevolution, different relationships have been formed between insects and fungi such as the pattern of the insect infection and mycosis by parasitic fungi. Similar to the distribution features of diverse insect species, fungal parasites are largely cosmopolitan and sympatrically distributed in different ecosystems [3]. For example, it has been reported that the propagules of the ascomycete Metarhizium and Beauveria species could reach up to $10^{6}$ CFUs (colony forming units) per gram of soil [4-6]. It is therefore conceivable that the multiple species or strain spores of fungal parasites can land on individual insect hosts to theoretically trigger co-infections. In reality, however, the insect cadavers collected from the fields are always mycosed by a single species/strain of fungal parasites $[7,8]$. On the other hand, coenzootic or coepizootic fungal insect diseases have been frequently observed in the field, where the same or different species of insects were killed and mycosed by different strains or species of fungal parasites [8-10]. Regarding the competition and coexistence of the multiple parasites of plants and mammals, different models have been proposed by 
theoretical ecology, such as the competitive exclusion [11,12], competition-colonization tradeoffs [13,14], and modern coexistence theory [15]. The model and fate-determining factors remain unclear regarding the competition for niches, including hosts, between insect pathogenic fungi.

Except for the elusive pattern of competition, different species of entomopathogenic fungi have been developed and used as environmentally-friendly mycoinsecticides for biocontrol of insect pests $[16,17]$. In particular, efforts were considered to co-formulate the spores of different strains or species of pathogenic fungi for better control of insect pests by overcoming environmental constraints such as irregular temperature fluctuations [18-20]. However, the synergistic effect was not evident or questioned [18]. The potential or degree of cross inhibition between entomopathogens was largely overlooked before coformulations.

Field application and recovery studies revealed that the inundative application of mycoinsecticide agents such as B. bassiana did not displace local population. Instead, different genotypic strains coexist in the field by infection of different insects, and less than $3 \%$ of the insect cadavers were mycosed by the released strains $[7,21]$. These kinds of studies have not investigated the effect of biocontrol releases on other species of fungal parasites. Entomopathogenic fungi infect hosts through penetration of insect cuticles and then colonization of insect hemocoels by overcoming host immunities [22]. It is still unclear regarding the stage-wise competition and factors that may essentially determine the competitive coexistence of fungal insect parasites.

In this study, we sought to provide empirical insights into the outcomes and patterns of competition between fungal insect parasites. By coinfection of insects with different species and strains of $M$. robertsii and B. bassiana each with a wide host range, we report the dominant mycosis of insect individuals by one species or one strain of the parasites. The model of competitive exclusion is empirically suggested in dependent or independent associations with factors such as the insect host species, initial titer, infection order, and growth media.

\section{Materials and Methods}

\subsection{Fungal Strains and Growth Assays}

Parasitic fungal strains of B. bassiana ARSEF 2860 (mating type, MAT1-1; abbreviated as Bb), ARSEF 8028 (MAT1-2) [23], and M. robertsii ARSEF 23 (MAT1-1; abbreviated as Mr) and ARSEF 2575 (MAT1-1) [24] were used in this study. In addition, red or green fluorescent protein (RFP/GFP) labeled strains were either generated by controlling gene expression with a constitutive promoter (i.e., the Tef gene promoter used for gene expression in Metarhizium and Gpd gene promoter used in Beauveria) or obtained from previous studies [25,26], including 2860-RFP, 8028-GFP, 23-GFP, and 2575-RFP strains. Fungal cultures were maintained on potato dextrose agar (PDA; BD Difco, Sparks Glencoe, MD, USA) for two weeks for harvesting conidial spores for bioassays against different insects. For growth assays, fungal strains were inoculated either individually $\left(2 \mu \mathrm{L}\right.$ of $1 \times 10^{6}$ conidia $\left./ \mathrm{mL}\right)$ on PDA plates (9 $\mathrm{cm}$ in diameter) or in pairs on the same plates $(2 \mathrm{~cm}$ spacing). To test the co-culturing in liquid medium, fungi were grown in Sabouraud dextrose broth (SDB, BD Difco, Sparks Glencoe, MD, USA) in a rotary shaker (190 rpm) for different times.

\subsection{Insect Bioassays}

Different fungal species/strains and their spore mixtures were used for both topical infection and injection assays against the last instar larvae of the wax moth Galleria mellonella, the females of the fruit fly Drosophila melanogaster, and the last instar larvae of the mealworm Tenebrio molitor. The wax moth and mealworm larvae were ordered from the company Keyun (Jiyuan, China). The fruit flies were reared on a standard cornmeal-agar medium at $25{ }^{\circ} \mathrm{C}$, and the two-day-old adults post eclosion were used for bioassays [27]. The conidial suspensions of each strain were adjusted in $0.01 \%$ Tween 20 to the concentration of $1 \times 10^{7}$ conidia $/ \mathrm{mL}$ for topical infection assays, and $1 \times 10^{6}$ conidia $/ \mathrm{mL}$ for injections. 
Spore mixtures were prepared by mixing the suspensions of two fungal species or strains at the volume ratios of 1:9, 1:1, and 9:1, respectively. For topical infections, insects were immersed in spore suspensions for $30 \mathrm{sec}$. To examine the potential priority effect of fungal infection, we conducted topical infection of insects by treatment with either $\mathrm{Bb}$ or $\mathrm{Mr}$ for 16 and $24 \mathrm{~h}$ first and then re-immersion of the insects in $\mathrm{Mr}$ or Bb spore suspensions. For injections, each insect was injected with $20 \mu \mathrm{L}$ of spore suspension from the second proleg using a micro-injector (Burkard manufacturing, Rickmansworth, UK). The insects immersed in or injected with $0.01 \%$ Tween 20 were used as reference controls. Insect mortality was recorded every $12 \mathrm{~h}$. The median lethal time $\left(\mathrm{LT}_{50}\right)$ of insects was estimated for each treatment, and the difference of insect survivals between treatments was calculated by Kaplan-Meir analysis [28]. The GFP/RFP-labelled strains were used for the same treatments. The newly dead insects were bled to count the fluorescent fungal cells formed within insect body cavities using a fluorescent microscope (Nikon Eclipse Ni, Tokyo, Japan).

For mycosis assays, the dead insects were lined on the moisturized filter papers for two weeks, and the mycosis ratio of insects by either or both fungi was estimated. Each treatment had three replicates (20 insects per replicate) and the experiments were repeated at least twice. After infection with the GFP-RFP-labelled strains, the fluorescent conidia formed on mycosed insects were then counted. The differences between the treatments with different species or strains were compared using the two-tailed Student's $t$-test.

\subsection{Penetration Test}

To determine whether there was a cross-inhibition effect on fungal penetration, we inoculated both individual and mixed fungal spores on cellophane membranes lined on a minimal medium agar $\left(\mathrm{NaNO}_{3}, 6 \mathrm{~g} / \mathrm{L} ; \mathrm{KCl}, 0.52 \mathrm{~g} / \mathrm{L} ; \mathrm{MgSO}_{4} 7 \mathrm{H}_{2} \mathrm{O}, 0.52 \mathrm{~g} / \mathrm{L} ; \mathrm{KH}_{2} \mathrm{PO}_{4}\right.$, $0.25 \mathrm{~g} / \mathrm{L}$; agar, $15 \mathrm{~g} / \mathrm{L}$ ) [29]. The spore suspensions of $\mathrm{Bb}$ and $\mathrm{Mr}$ were prepared in $0.01 \%$ Tween 20 to a final concentration of $5 \times 10^{6}$ conidia $/ \mathrm{mL}$, and a mixture was prepared at the volume ratio of 1:1. The spore suspensions ( $2 \mu \mathrm{L}$ each) were then individually inoculated on cellophane for three days. The membranes were then carefully removed together with fungal cultures, and the plates were then kept for incubation for an additional seven days to determine the outgrowth or not of fungal cultures [30]. Each treatment had 15 plates, and the experiments were repeated three times.

\subsection{Germination and Appressorium Formation Assays}

Spore suspensions ( $20 \mu \mathrm{L}$ each; $1 \times 10^{8}$ conidia $/ \mathrm{mL}$ ) of $\mathrm{Bb}, \mathrm{Mr}$, and $\mathrm{Bb}: \mathrm{Mr}$ (1:1) were transferred to petri dishes $(9 \mathrm{~cm}$ in diameter) containing $2 \mathrm{~mL}$ of the minimum medium containing $1 \%$ glycerol [31]. After incubation for $18 \mathrm{~h}$, germination of both fungi and appressorium formation of Mr were examined under microscopy [30]. There were three replicates for each treatment, and at least five to six microscopic fields were examined for estimation of the fungal germination and appressorium formation rates.

\subsection{Liquid Incubation and Biomass Quantification}

To determine the growth competition between $\mathrm{Bb}$ and $\mathrm{Mr}$ in artificial medium, we inoculated the spore suspension ( $1 \mathrm{~mL}$ each of $1 \times 10^{8}$ conidia $/ \mathrm{mL}$ ) of $\mathrm{Bb}, \mathrm{Mr}$, and $\mathrm{Bb}: \mathrm{Mr}$ (at the ratios of 1:9; 1:1, and 9:1) into flasks $(250 \mathrm{~mL}$ ) containing $100 \mathrm{~mL} \mathrm{SDB}$ medium. Mycelia were harvested seven days post incubation in a rotary incubator at $25{ }^{\circ} \mathrm{C}$ and $190 \mathrm{rpm}$. The samples were washed thrice with sterile water, dried at $65^{\circ} \mathrm{C}$ overnight and weighed. There were five replicates for each treatment, and the experiments were repeated twice. To determine $\mathrm{Bb}$ and $\mathrm{Mr}$ cell ratio in co-cultures, mycelia of the three mixtures (i.e., $\mathrm{Bb}: \mathrm{Mr}$ at the ratios of 1:9,1:1, and 9:1) were harvested three and seven days post inoculation, and the dried samples $(0.1 \mathrm{~g}$ each) were used for DNA extractions with a Hi-DNAsecure plant kit (TIANGEN, Beijing, China). After quantification, $1 \mathrm{pg}$ of the plasmid pDHt-Bar was added into each DNA sample as a reference for real-time quantitative PCR analysis. PCR primers were designed for the Bar gene (BarF: GGAGGTCAACAATGAATGCC; BarR: ATGTCCTCGTTCCTGTCTGC; product size, $171 \mathrm{bp}$ ), the LysM effector Blys2 gene [25] 
for Bb (Blys2F: ACCACTCTCACTACCGCTGT; Blys2R: CCTTGCCTGAATGAAGAGTT; product size $160 \mathrm{bp}$ ), and the perilipin $\mathrm{Mpl1}$ gene [32] for Mr (Mpl1F: TGTACAACGACACTCGCAGC; Mpl1R: CGACAAAGGCGGTAGAGACA; product size, 156 bp). After reaction, the DNA ratio of either $\mathrm{Bb}$ or Mr in different mixtures was calculated by reference to the spike-in plasmid DNA. The experiments were repeated twice.

\section{Results}

\subsection{Non-Synergistic Effect of Coinfection on Fungal Virulence}

To determine the virulence effect and mycosis fate of coinfection, we first used the B. bassiana strain ARSEF 2860 and M. robertsii strain ARSEF 23 for different experiments. These two strains had different growth rates on PDA; that $\mathrm{Mr}$ grew faster that $\mathrm{Bb}$ was evident after inoculation for 6 or 11 days ( $t$-test: $\mathrm{df}=4, t>14, p<0.001$ ) (Figure S1A). After topical infection of the wax moth larvae, we found that the insects infected by $\mathrm{Mr}$ (with a median lethal time $\mathrm{LT}_{50}=108 \pm 4.2 \mathrm{~h}$ ) died faster (log-rank test: $\mathrm{df}=1, \chi^{2}=10.75$, $p=0.001)$ than those treated with $\mathrm{Bb}\left(\mathrm{LT}_{50}=104 \pm 4.0 \mathrm{~h}\right)$. The insect survival curves of those coinfections were largely in the middle of the dynamics caused by two individual strains (Figure 1A; Table S1). For injection assays, the survival trends of insects were rather similar to those treated by topical infections. The results showed that $\mathrm{Mr}\left(\mathrm{LT}_{50}=72 \pm 1.3 \mathrm{~h}\right)$ killed insects faster (log-rank test: $\left.\mathrm{df}=1, \chi^{2}=11.12, p=0.0009\right)$ than $\mathrm{Bb}\left(\mathrm{LT}_{50}=84 \pm 0.64 \mathrm{~h}\right)$, and the survival of co-injection treatments had no significant difference with that of $\mathrm{Bb}$ injection but was in sharp contrast to that of Mr treatment (Figure 1B; Table S2).
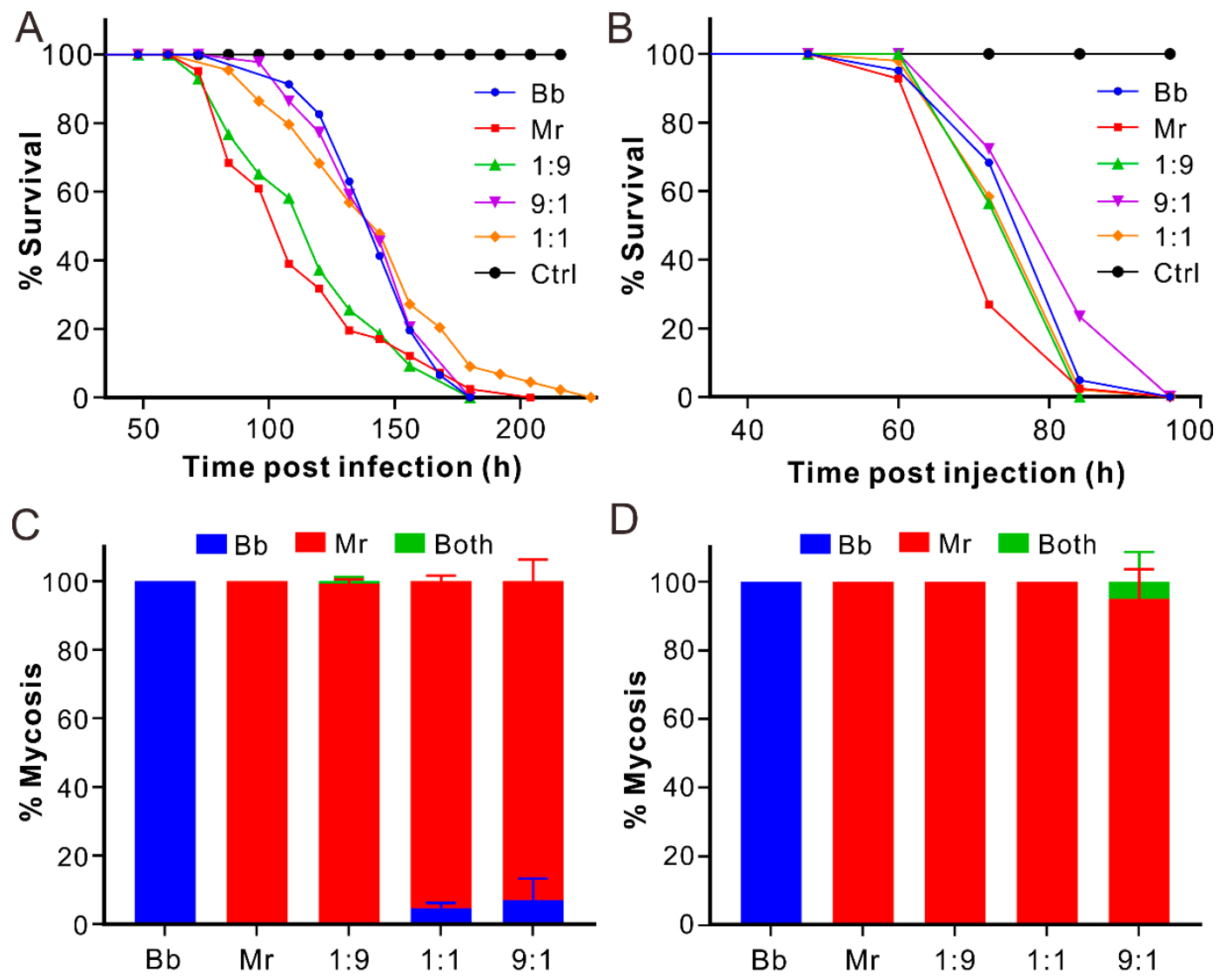

Figure 1. Cont. 

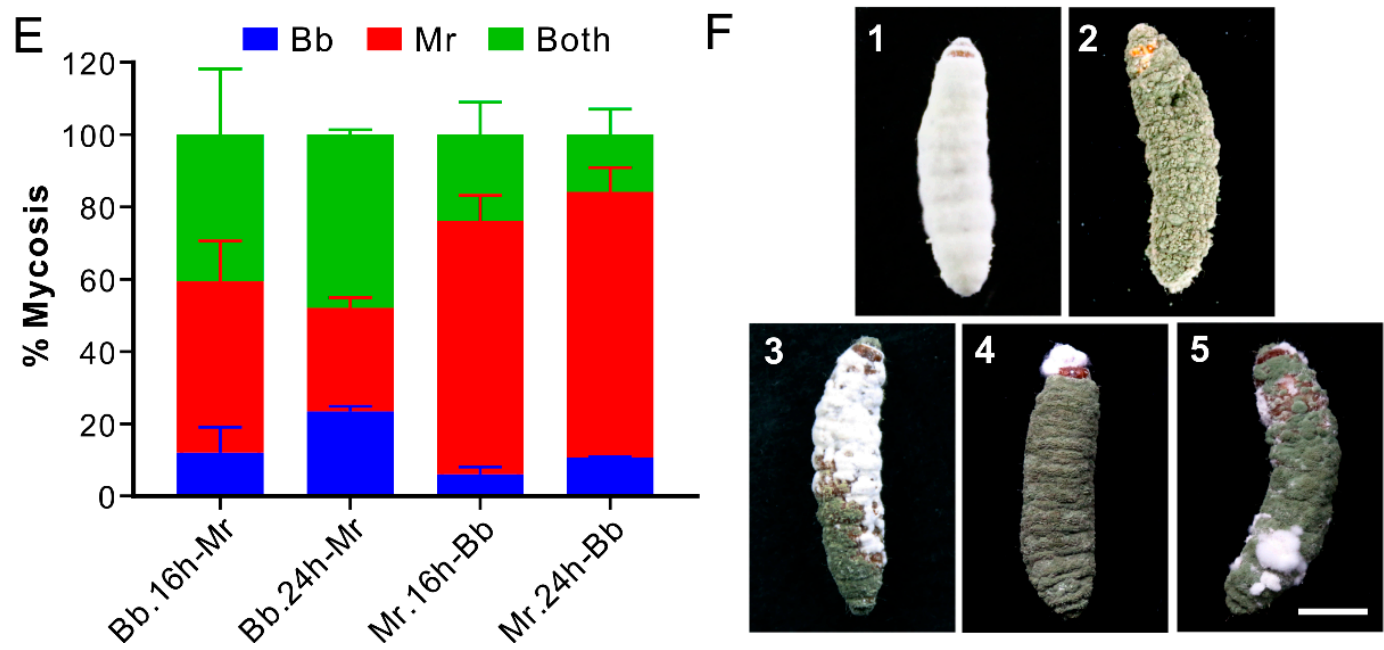

Figure 1. Insect survival and mycosis. (A) Survival of the wax moth larvae after topical infection. (B) Survival of the wax moth larvae after injection. (C) Percentage of the insect mycosis after topical infection of different parasites. (D) Percentage of the insect mycosis after injection of different parasites. (E) Percentage of the insect mycosis after sequential infection of different parasites. Strains: Bb, Beauveria bassiana ARSEF 2860; Mr, Metarhizium robertsii ARSEF 23. Treatments such as $\mathrm{Bb} .16 \mathrm{~h}-\mathrm{Mr}$ and $\mathrm{Bb} .24 \mathrm{~h}-\mathrm{Mr}$ mean that the insects were treated with the Bb spore suspension for $16 \mathrm{~h}$ or $24 \mathrm{~h}$ and then re-treated with the Mr suspension and vice versa. (F) Different type of mycosed insect cadavers. (1) A larva mycosed by Bb; (2) a larva mycosed by Mr; (3-5) larvae mycosed by both fungi in different types. Bar, $1 \mathrm{~cm}$

For topical infection of either the mealworm larvae or fruit fly females, a non-synergistic effect of coinfections was similarly observed. Mr killed flies faster (log-rank test: $\mathrm{df}=1$, $\left.\chi^{2}=80.22, p<0.0001\right)$ than $\mathrm{Bb}$, and the $1: 1$ ratio coinfection curve was in the middle (Figure S2A; Table S3). For mealworm larvae, no obvious difference was observed (logrank test: $\mathrm{df}=2, \chi^{2}=3.21, p=0.073$ ) for insect survival after topical infection with the spore suspensions of $\mathrm{Bb}, \mathrm{Mr}$, and $\mathrm{Bb}$ / Mr mixture (1:1) (Figure S2B; Table S4).

\subsection{Dominant Mycosis of Insect Cadavers by Metarhizium}

After estimation of insect mycosis ratios, unexpectedly we found that the wax moth cadavers were largely mycosed by Mr during both topical infection and injection assays. For example, with topical coinfection at the $\mathrm{Bb}: \mathrm{Mr}$ ratio of 1:9, the cadavers were almost completely mycosed by $\mathrm{Mr}$, and more than $90 \%$ of the cadavers were colonized by $\mathrm{Mr}$ at the Bb:Mr ratios of 1:1 and even 9:1 (Figure 1C). The mycosis rates were more highly biased towards $\mathrm{Mr}$ after the co-injections than topical coinfection assays. The former treatments resulted in the dominant occupation of insect cadavers by $\mathrm{Mr}$ at the $\mathrm{Bb}: \mathrm{Mr}$ ratios of 1:9, 1:1, or 9:1 and a few cases of co-mycosis (i.e., the single cadaver mycosed by two fungi) at the 9:1 ratio (Figure 1D,F). The dead flies were also highly mycosed by $\operatorname{Mr}(>90 \%)$ after topical coinfection of $\mathrm{Bb} / \mathrm{Mr}$ (1:1) (Figure S3A). For mealworms, however, the mycosis ratio of the coinfection treatment (1:1) varied in the increasing order of $\mathrm{Bb}(11.3 \pm 1.5 \%)$, $\operatorname{Mr}(30.0 \pm 3.0 \%)$, and co-mycosis $(58.7 \pm 2.3 \%)$ (Figure S3B). Thus, the species of insect hosts can affect the fate of mycosis after coinfection.

\subsection{Biased Mycosis of Insect Cadavers after Sequential Infections}

After the tests of priority effects, it was found that the Bb-first treatments did not result in the dominance of $\mathrm{Bb}$ mycosis; instead, the later treated $\mathrm{Mr}$ or co-mycosis took the bigger proportions (Figure 1E). For example, $24 \mathrm{~h}$ post immersion of Bb spores, further treatment with $\mathrm{Mr}$ resulted in $28.6 \pm 2.8 \%$ of the Mr-mycosed cadavers and $47.9 \% \pm 1.4$ of co-mycosis by both $\mathrm{Bb}$ and $\mathrm{Mr}$. However, the $\mathrm{Mr}$-first treatments largely resulted in the Mr-mycosed cadavers, e.g., $70.1 \pm 6.9 \%$ for the $\mathrm{Mr}$ inoculation for $16 \mathrm{~h}$ followed by the $\mathrm{Bb}$ treatment; and $73.5 \pm 6.7 \%$ for the $\mathrm{Mr}$ inoculation for $24 \mathrm{~h}$ followed by the $\mathrm{Bb}$ treatment. The ratios were both significantly higher than those mycosed by $\mathrm{Bb}(t$-test: $\mathrm{df}=2, t>12$, 
$p<0.01$ ) (Figure 1E). Thus, the priority effect was not applicable to Bb. The phenotypes of insect mycosis are shown in Figure 1F. It is noteworthy that Mr usually took the bigger part of cadavers than $\mathrm{Bb}$ did during co-mycosis.

\subsection{Dual Inhibition of Spore Germination or Appressorium Formation}

After examining the effect of conidial mixture on spore germination and induction of appressorium formation, it was found that the germination rate of the Mr spores in mixture (1:1) had no difference to that of the solo Mr spores. However, Bb spore germination was significantly ( $t$-test: $\mathrm{df}=4, t=14.33, p=0.0001$ ) reduced in mixture when compared with its germination alone in medium (Figure $2 \mathrm{~A}, \mathrm{~B}$ ). In contrast to $\mathrm{Bb}, \mathrm{Mr}$ spores germinate and produce the infection structure appressoria on hydrophobic surface. The appressorium formation rate of $\mathrm{Mr}$ in mixture was substantially $(t$-test: $\mathrm{df}=4, t=5.34, p=0.0059)$ reduced when compared with that of the solo Mr cells (Figure 2A,C). We also tested fungal penetration of cellophane membranes. Three days post inoculation, we found that $\mathrm{Mr}$ but not $\mathrm{Bb}$ could penetrate the membrane, and the inoculation of the $\mathrm{Bb} / \mathrm{Mr}$ spore mixture (1:1) failed in penetrating the membrane (Figure 2D). Thus, an antagonistic effect was evident between fungi from the start of spore germination and differentiation.
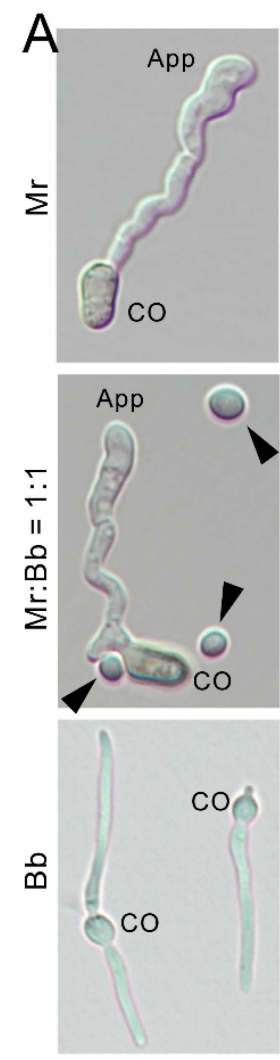
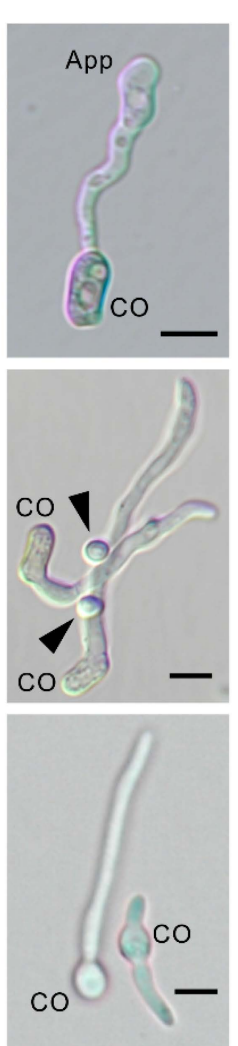
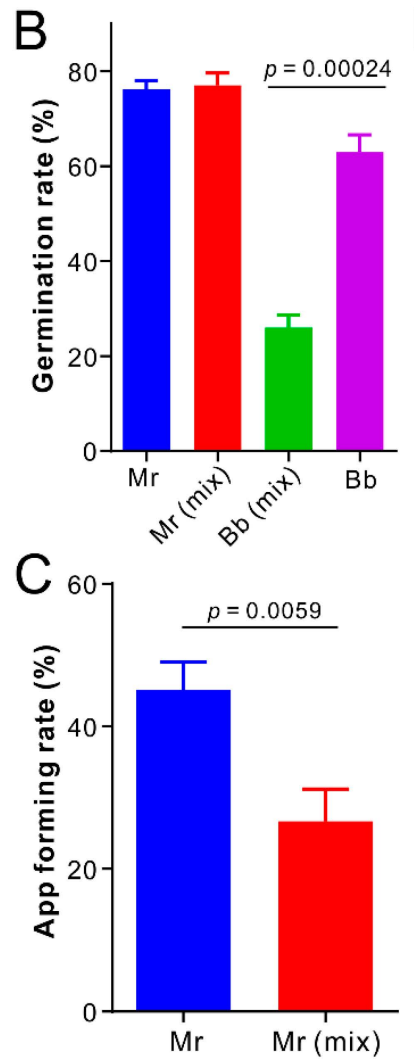
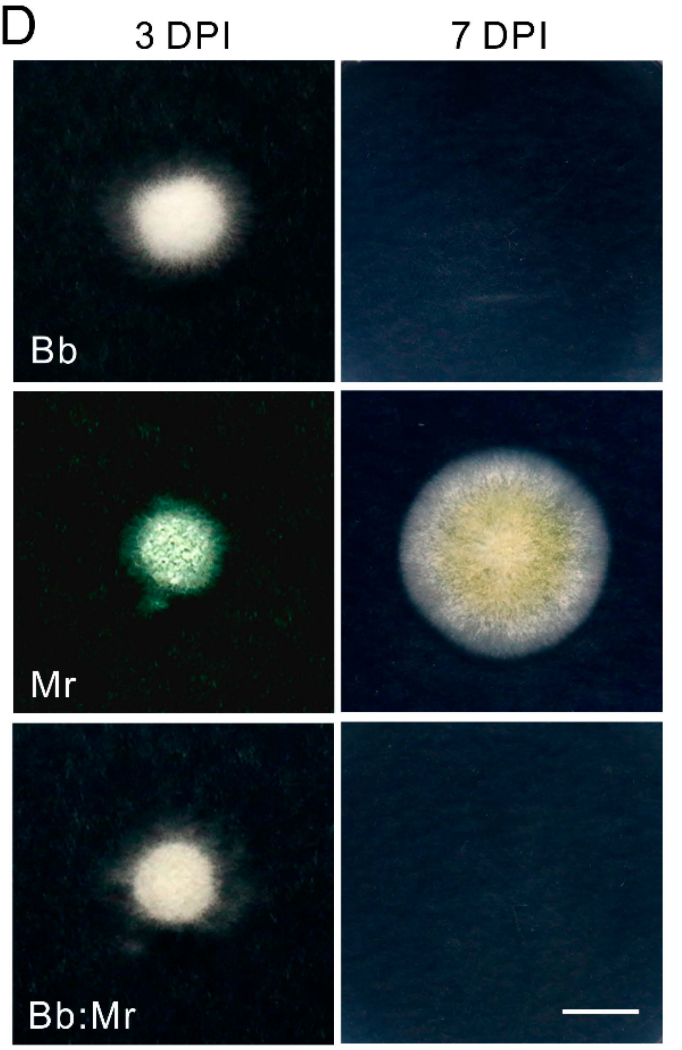

Figure 2. Dual inhibitions on spore germination, appressorium formation, and fungal penetration. (A) Microscopic imaging of spore germination and appressorium formation. Strains: Bb, Beauveria bassiana ARSEF 2860; Mr, Metarhizium robertsii ARSEF 23. CO, conidium; App, appressorium. Un-germinated Bb spores were arrowed in the mixing treatment (i.e., $\mathrm{Bb}: \mathrm{Mr}=1: 1$ ). Bar, $5 \mu \mathrm{m}$. (B) Statistic of spore germination. $\mathrm{Mr}$ (mix) or $\mathrm{Bb}$ (mix) means the germination ratio of $\mathrm{Mr}$ or $\mathrm{Bb}$ spores in the mixture (1:1) treatment. (C) Comparative estimation of the Mr appressorium formation in pure and mixed cultures. (D) Penetration assays of $\mathrm{Bb}, \mathrm{Mr}$, and $\mathrm{Bb}: \mathrm{Mr}(1: 1)$ against the cellophane membrane. The membranes were carefully removed with fungal cultures three days post inoculation (DPI) and kept for incubation for additional seven days. Bar, $1 \mathrm{~cm}$. 


\subsection{One-Sided Dominance of M. robertsii within Insect Hemocoels}

Next, we tested fungal competition within insect body cavities by injection of the wax moth larvae with the RFP or GFP-labelled $\mathrm{Bb}$ and $\mathrm{Mr}$ spores or their mixtures. The same time $(60 \mathrm{~h})$ post injection, a large amount of the hyphal body $(\mathrm{HB})$ cells could be produced by either $\mathrm{Bb}$ or $\mathrm{Mr}$ alone within insect hemocoels (Figure $3 \mathrm{~A}, \mathrm{~B})$. For the co-injections, the $\mathrm{HB}$ cells of RFP-Bb could be hardly detected in insect hemolymph for the treatment of the $\mathrm{Bb} / \mathrm{Mr}$ mixture at a 1:9 ratio, i.e., being fully occupied by $\mathrm{Mr}$ cells. For the co-injection of the $\mathrm{Bb} / \mathrm{Mr}$ mixtures at either 1:1 ( $t$-test: $\mathrm{df}=2, t=55.67, p=0.0003)$ or 9:1 ( $t$-test: $\mathrm{df}=2$, $t=9.89, p=0.01)$ ratios, significantly fewer RFP-Bb cells could be observed when compared with the GFP-Mr cells in insects (Figure 3C-E). Thus, $\mathrm{Mr}$ could markedly outcompete $\mathrm{Bb}$ within the insect body cavity.
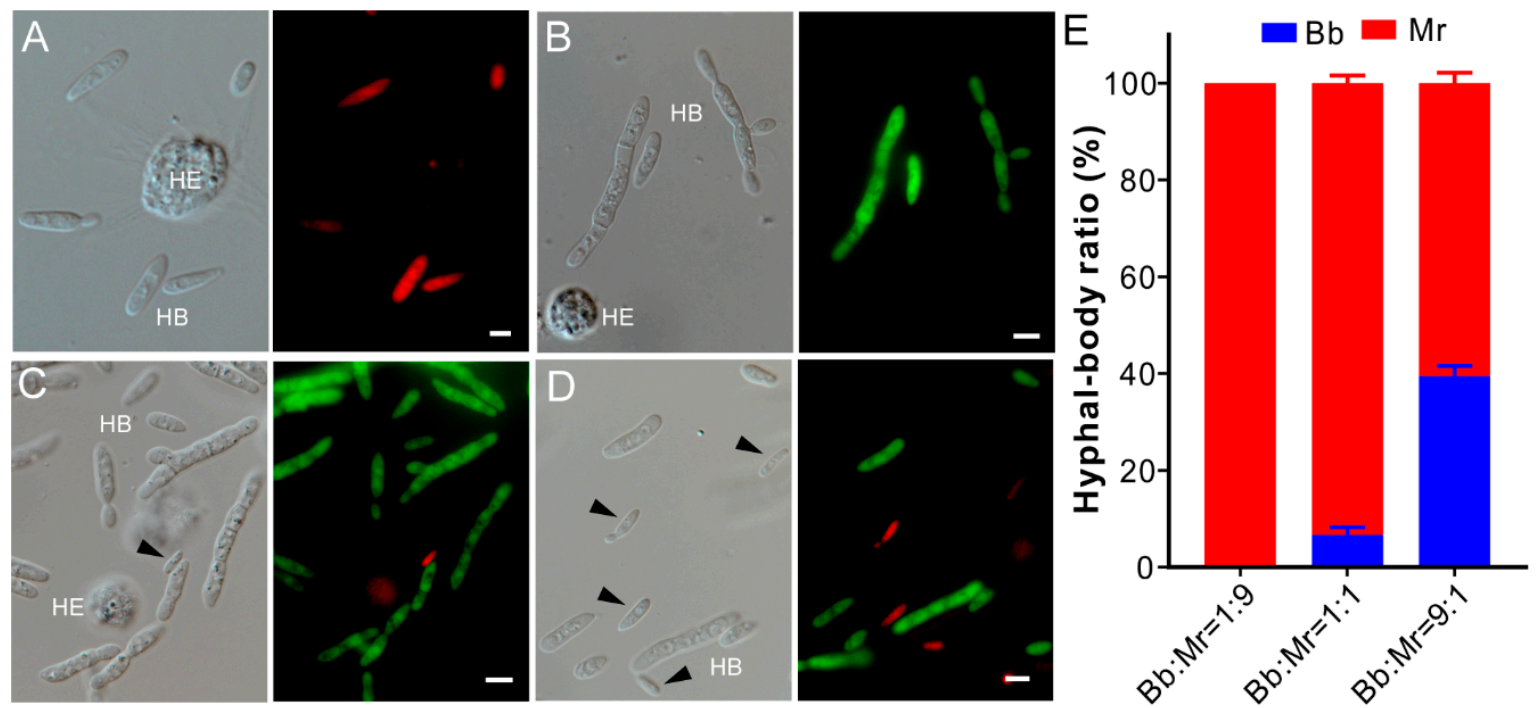

Figure 3. Parasite competition within insect hemocoels. (A) Hyphal body (HB) cells of the RFP-labelled Bb formed in insects. (B) HB cells of the GFP-labelled Mr formed in insects. (C) HB cells formed in insects of both fungi injected with the suspension mixture at the $\mathrm{Bb} / \mathrm{Mr}$ ratio of 1:1. (D) $\mathrm{HB}$ cells formed in insects of both fungi injected with the suspension mixture at the $\mathrm{Bb} / \mathrm{Mr}$ ratio of 9:1. The insects were bled for imaging $60 \mathrm{~h}$ post injection. For each panel, the left ones show the bright-field image and the right ones show the corresponding fluorescence image. HE, insect hemocyte; Bb cells are arrowed in panels (C,D). Bar, $5 \mu \mathrm{m}$. (E) Ratio estimation of the HB cells formed within insects after injection with spore mixtures for $60 \mathrm{~h}$. Strains: Bb, Beauveria bassiana ARSEF 2860; Mr, Metarhizium robertsii ARSEF 23.

\subsection{Dominance of B. bassiana during Co-Culturing in Artificial Medium}

Seven days post co-culturing in SDB (Figure $4 \mathrm{~A}$ ), Bb mycelial biomass was significantly higher ( $t$-test: $\mathrm{df}=4, t=8.31, p=0.0014)$ than that of $\mathrm{Mr}$, indicating that $\mathrm{Bb}$ grew faster than $\mathrm{Mr}$ in liquid medium. The biomasses of the co-cultures $\mathrm{Bb} / \mathrm{Mr}$ at the 9:1 and 1:1 ratios were significantly higher ( $t$-test: $\mathrm{df}=4, t>9, p<0.001$ ) than that of solo $\mathrm{Mr}$, whereas the $\mathrm{Bb} / \mathrm{Mr}$ 1:1 and 1:9 biomasses were considerably lower $(t$-test: $\mathrm{df}=4, t>3, p<0.05)$ than that of solo $\mathrm{Bb}$ (Figure $4 \mathrm{~B}$ ). We also performed DNA quantification analysis, and the results indicated that $\mathrm{Bb}$ could outcompete $\mathrm{Mr}$ from an equal start. At the 1:1 inoculation ratio, Mr only took $19.5 \pm 3.2 \%$ of the co-cultures three days post inoculation, but $15.8 \pm 4.1 \%$ of the co-cultures seven days post inoculation (Figure $4 \mathrm{C}, \mathrm{D}$ ). At the $\mathrm{Bb} / \mathrm{Mr}$ ratio of 9:1, Mr could be almost completely wiped off after co-culturing for seven days (Figure 4D). After co-inoculation of the RFP-Bb and GFP-Mr spores in SDB at the 1:1 ratio, microscopic examination indicated that $\mathrm{Bb}$ but not $\mathrm{Mr}$ started to produce blastospores $24 \mathrm{~h}$ post inoculation, and a large amount of these propagules could be produced by $\mathrm{Bb}$ after inoculation for $48 \mathrm{~h}$ (Figure S4). This kind of strategy might be helpful for Bb to quickly outcompete Mr during co-growth in artificial medium. 
A

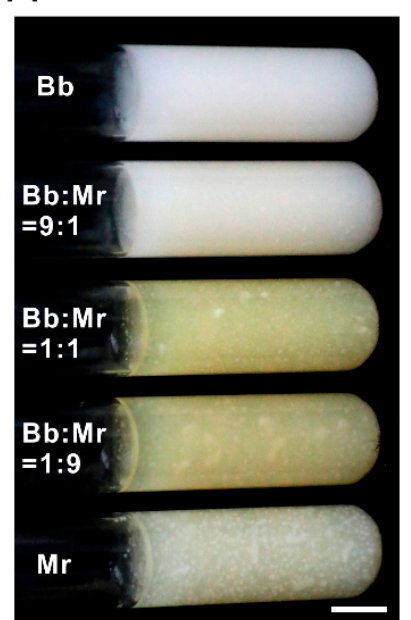

C

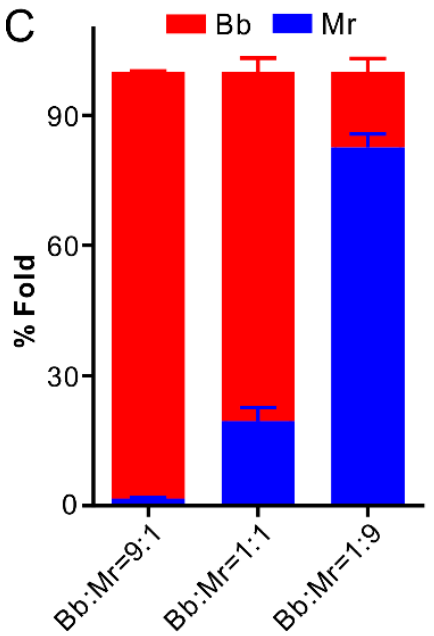

B
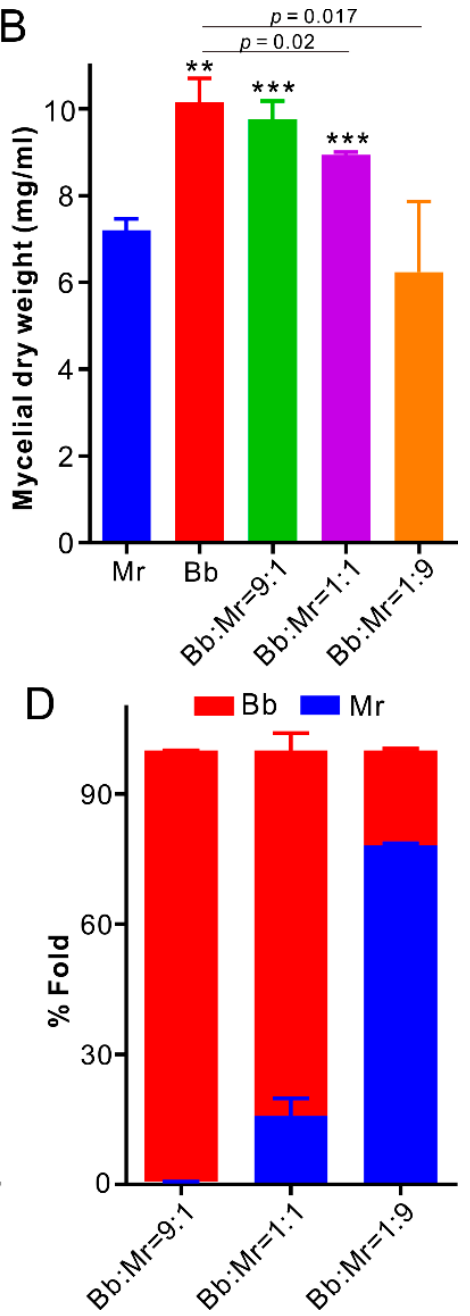

Figure 4. Parasite competition in liquid medium. (A) Phenotype of fungal cultures. Fungal spores or spore mixtures were inoculated in SDB for seven days. Bar, $1 \mathrm{~cm}$. (B) Comparison of mycelial biomasses. The significance of the difference was tested against either $\mathrm{Mr}$ or $\mathrm{Bb}$. The asterisks above columns showing the comparison with $\mathrm{Mr}$ at the difference level: ${ }^{* *} p<0.01$; ${ }^{* * *} p<0.001$. The $p$ values showing above the columns indicate the difference levels between $\mathrm{Bb}$ and relative mixture treatments, i.e., $p=0.02$ between $\mathrm{Bb}$ and $\mathrm{Bb}: \mathrm{Mr}=1: 1 ; p=0.017$ between $\mathrm{Bb}$ and $\mathrm{Bb}: \mathrm{Mr}=1: 9$. Quantification analysis of fungal DNA ratio in co-cultures three $(\mathbf{C})$ and seven $(\mathbf{D})$ days post inoculation. Strains: $\mathrm{Bb}$, Beauveria bassiana ARSEF 2860; Mr, Metarhizium robertsii ARSEF 23.

\subsection{Biased Mycosis of Insects after Infection with Different Strains}

Next, we were curious to know the outcome of competitions between strains. For two Mr strains, ARSEF 23 grew faster than ARSEF 2575 ( $t$-test: $\mathrm{df}=4 ; t=6.41, p=0.003$ for the cultures 11 day post inoculation) (Figure S1B), and the Bb strain ARSEF 8028 grew faster than ARSEF 2860 on PDA ( $t$-test: $\mathrm{df}=4, t=5.88, p=0.0042$ for the cultures 11 day post inoculation) (Figure S1C). The non-synergistic effect on virulence was similarly evident in the experiments of both topical infection and infection assays (Figure S5; Tables S5-S8). For example, the Metarhizium strain ARSEF 23 could more quickly (log-rank test: $\mathrm{df}=1$, $\left.\chi^{2}=50.01, p<0.0001\right)$ kill insects than ARSEF 2575 during topical infection of the wax moth larvae, and the insect survival curves of their mixtures were in between the dynamics of the two mother strains. Insect survivals were similar (log-rank test: $\mathrm{df}=1, \chi^{2}=0.17, p=0.682$ ) after topical infection of two Beauveria strains, and the non-significant relationship of insect survival was generally observed between each mother strain and their mixtures. 
Considering that the cadavers are indistinguishable after mycosis by different strains of either Metarhizium or Beauveria, the fluorescent protein-labelled strains were generated and used for mycosis assays. Thus, the spores of the obtained 23-GFP and 2575-RFP of M. robertsii, and the 2860-RFP and 8028-GFP of B. bassiana were mixed (1:1), respectively, to co-inject the wax moth larvae. After insect mycosis, we found that the fluorescent spores were unequally produced on insects. For two Metarhizium strains, 23-GFP spores were largely $(56.5 \pm 4.1 \%)$ produced on cadavers over 2575 -RFP spores $(29.7 \pm 7.1 \%$; $t$-test: $\mathrm{df}=8$, $t=7.36, p=0.005)$. It was interesting to find a proportion of spores $(13.8 \pm 3.8 \%)$ containing both the GFP and RFP signals (Figure 5A,B), an indication of parasexual recombination. For the coinfections with two Beauveria strains, it was found that 2860-RFP $(84.1 \pm 14.3 \%)$ dominated the mycosis of insect cadavers over 8028-GFP $(15.9 \pm 14.1 \%$; $t$-test: $\mathrm{df}=8$, $t=5.85, p=0.004$ ) (Figure 5C,D). In contrast to the Metarhizium strains, these two Beauveria strains did not produce progenies containing the signals of both fluorescent proteins after co-infection of insects.
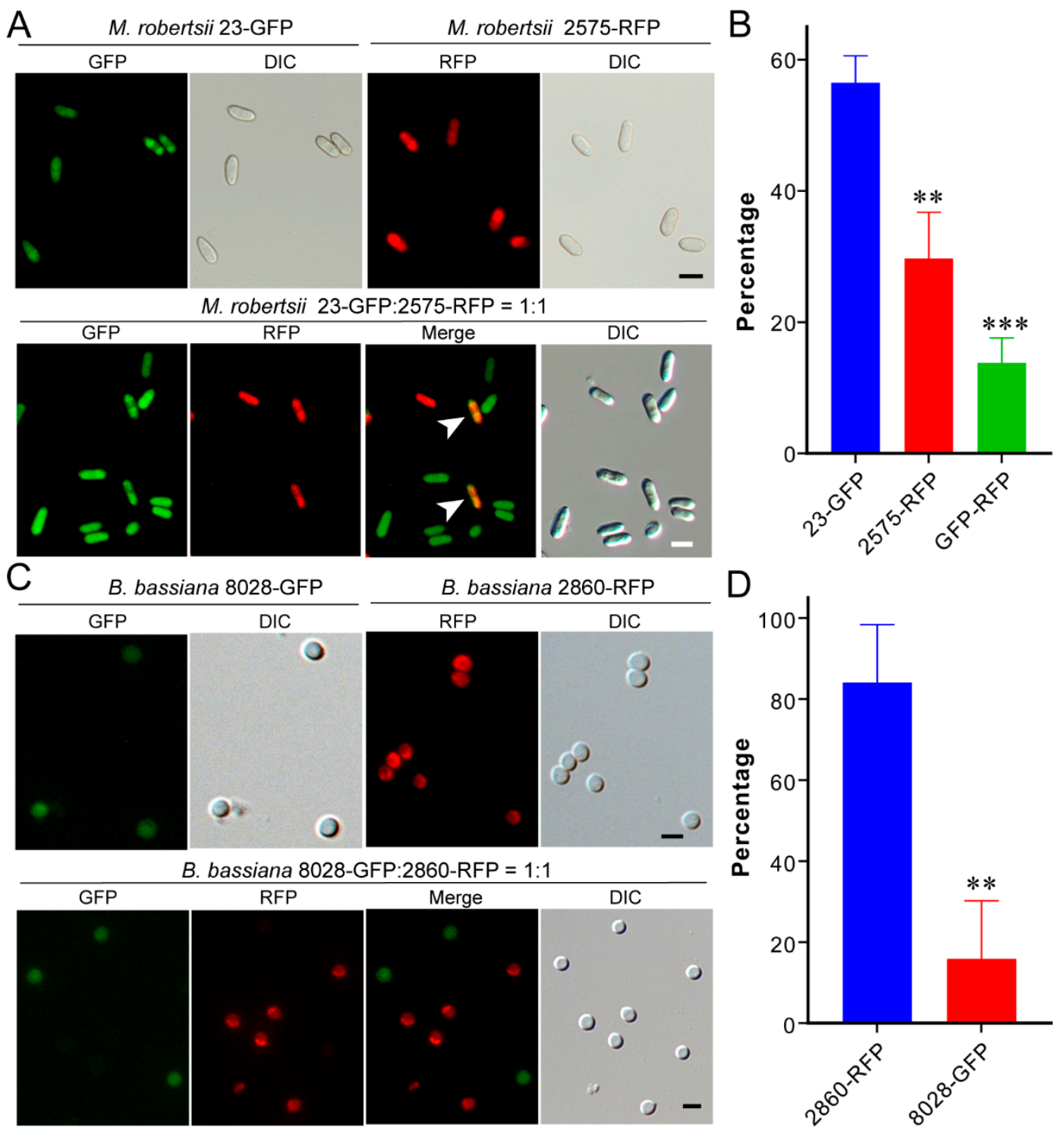

Figure 5. Competition between fungal strains in mycosis of insect cadavers. (A) Fluorescent conidia produced by two Metarhizium strains on insect cadavers. Conidial spores containing both GFP and RFP signals were arrowed. Bar, $5 \mu \mathrm{m}$. (B) Percentage of the Metarhizium spores with different types of fluorescent signals. (C) Fluorescent conidia produced by two Beauveria strains on insect cadavers. Bar, $5 \mu \mathrm{m}$. (D) Percentage of the Beauveria spores with different types of fluorescent signals. The asterisks above the columns of the panels B and D show the difference levels between strains at ${ }^{* *} p<0.01 ;{ }^{* * *} p<0.001$. 


\section{Discussion}

It is common that mammal or plant individuals are infected at the same time by multiple parasites [33-36]. Different models or theories have been proposed; however, empirical supports are largely needed. In this study, we performed coinfections of insects with different species or strains of fungal parasites and found that the relatively small-sized insect individuals were killed and largely mycosed by a single species/strain. Consistently, previous coinfection of insects also resulted in the dominant mycosis of insects by single species of parasitic fungi $[18,37,38]$. Taken together, our empirical data suggest that the competitive exclusion principle (CEP) would fit for the pattern and outcome of fungal parasite competitions for insect individuals. Regarding the two examined species B. bassiana and $M$. robertsii, the latter would be a superior competitor since it could grow quicker and kill insects faster than B. bassiana. In addition, we found that the dominant mycosis of insect cadavers by $M$. robertsii was largely independent of its initial dosage titer in coinfection and the order of inoculation. Considering the diversity of competing species, CEP postulates that competitors can coexist if they occupy distinct ecological niches [12,39]. Indeed, the diverse species and strains of fungal insect parasites apparently co-occur in different ecosystems $[10,40,41]$. We also found that the "inferior" competitor B. bassiana could outcompete $M$. robertsii when two fungi were co-cultured in an artificial medium, a condition mimicking fungal saprophytic propagation in the field. Our findings thus not only support the fit for CEP between the competitions of fungal insect parasites but also unveil the alternative strategy employed by the inferior competitors to maintain their persistence in distinct niches. Except for the finding that $M$. robertsii grows more quickly than B. bassiana, an additional mechanism or mechanisms remains to be determined why the former can outcompete Beauveria in coinfections.

Ascomycete insect pathogens are closely related to plant pathogens and endophytes [42]. The DNA barcoding analysis of wood endophytes revealed that CEP was not applicable to these fungi since diverse fungal taxa were co-present in wood samples [43]. Instead, the model of competition-colonization tradeoffs has been suggested to mediate the competition and coexistence of the fungal mycorrhiza or pathogens since the diverse species of these fungi could either occupy different root tips $[13,44,45]$ or infect different parts of individual plants $[34,36]$. We found that the infection order of $M$. robertsii barely affected its dominant mycosis ability, i.e., the unidirectional competition without the obvious priority effect. It has also been found that the filed applications of the B. bassiana and M. robertsii strains for pest controls could persist in local populations for the long term $[7,46]$. Taken together, the modern coexistence theory, distinguished as a priority effect $[47,48]$, might also be inapplicable to the competition between insect parasites. Considering the high density, multispecies concurrence, and small-sized features of insects, the CEP patterns would therefore be common between the competitions of insect parasites. In contrast to the generalist B. bassiana and $M$. robertsii, each with broad host ranges, the entomopathogens such as the acridid-specific pathogen Metarhizium acridum and the zombie-ant fungi have narrow host ranges [24,49]. Further investigations are still required to determine the competition and coexistence patterns between those specialist pathogens as well as between fungal and non-fungal parasites.

The phrase within-host competition has been frequently used in theoretical ecologies. Actually, both animal and plant parasites/endophytes infect hosts through a multistep process of colonization. We examined the competition between two fungal parasites at both the outside and inside insect levels and found the competition actually occurred at both stages. At least due to the nutrient limitation on insect surfaces, it is not surprising to find that the dual inhibition of spore germination (B. bassiana) or appressorium differentiation (M. robertsii) occurred at the initial stage of fungal infection. At this stage, it could be concluded that $M$. robertsii outcompeted B. bassiana from the spore-germination point of view. The direct injection assays also evidenced that $M$. robertsii cells dominated insect hemocoels, which led to the exclusive mycosis of insect cadavers by this fungus. Thus, competitive exclusion occurred at different steps, probably at every step, between parasites 
during the infection and mycosis of insects. This kind of the dynamic dual inhibition and exclusive competition could explain why the synergistic effect was not observed in coinfections in this study and as being reported [50]. In this respect, the mixed use of fungal parasites for pest control is not recommended.

In addition to the wax moth larvae, our additional coinfections of fruit flies and mealworms revealed that $M$. robertsii dominated the mycosis of flies, but a much high ratio of co-mycosis occurred during the coinfection of mealworms. The results suggest that the divergent species of insect hosts might affect the outcomes of parasite competition. The host immune modulation of parasite competition has been proposed in parasite-host interactive systems [51,52]. At least, for example, different numbers and families of antimicrobial peptide genes are encoded by different insects [53]. It was intriguing to find that the coinfection of ants or termites with M. anisopliae and the facultative saprophyte Aspergillus species largely resulted in the mycosis of insect cadavers by Aspergillus. It was assumed that host immunity was first inhibited by Metarhizium, which led to the mycosis of insects by the fast-growing saprophytes [54,55]. The coinfection of ants with different Metarhizium strains and species (i.e., $M$. robertsii and M. brunneum) revealed that insect social immunity (sanitary care by grooming to reduce spore load) also affect the consequence of parasite competitions [56]. Thus, the host effect on competition can be species-dependent, which requires further investigation.

During co-culturing in artificial medium, we found that, in contrast to M. robertsii, B. bassiana evolved with the ability to produce blastospores shortly after inoculation that might enable the fungus to outcompete Metarhizium species. Thus, both the host and non-host patch traits may influence the outcomes of parasite competition and coexistence. In addition, different strains and species of fungal parasites also demonstrate the feature of host preference, manifested in the varied speed of insect killing $[7,57,58]$. Otherwise, the environmental factors such as temperature and ultraviolet radiation also affect the outcomes of competition and coexistence of fungal parasites $[19,20,50]$. Thus, along with the pattern of exclusive competition for individual insects, fungal insect parasites evolved with multiple ways/abilities to coexist in distinct ecological niches. It has been confirmed in recent years that the ascomycete insect pathogens such as Metarhizium and Beauveria species can form endophytic or rhizospheric relationships with plants for trading nutrients [59,60]. Obviously, it is the additional strategy for these fungi to maintain persistence or coexistence in the field, especially in the periodic seasons without insect hosts. The pattern of their competition for plants can be similar to other fungal endophytes or mycorrhiza but remains to be determined in the future.

It is mixed regarding the effect of species relatedness on their coexistence and competition, since the more closely related species can be either more or less likely to coexist [61]. The study of animals indicated that the inter-specific rivalry is usually greater than intraspecific competition [62]. We found that, unlike the CEP pattern of interspecies competition, intra-species coinfections resulted in the production of both genotypic spores on cadavers, even with a unidirectional bias towards one strain of either M. robertsii or B. bassiana. The sexual cycle of the heterothallic Metarhizium and Beauveria species rarely occurs in the field [63]. Instead, parasexual recombination takes place between compatible strains through the process of hyphal fusion, heterokaryosis, and mitotic crossing-over for limited genetic recombination $[7,63]$. We found a decent ratio of the Metarhizium spores containing both the GFP and RFP signals, good support for recombination between two examined strains. However, the case was not evident between two Beauveria strains, which might be due to the issue of heterokaryon incompatibility that can exclude competing kinships to limit the spread of harmful nuclear or cytoplasmic elements [64]. Thus, it seems that exclusive competition may occur between incompatible strains but recombination arises from the compatible strains of fungal insect parasites.

In conclusion, our empirical data support the principle of competitive exclusion fitting for the fungal parasite infection and mycosis of insect individuals at both the inter- and intra-species levels. Different species or strains of parasites can coexist sympatrically by 
occupying distinct ecological niches including the alternative infection of the individual insects belonging to the same or different species. In addition to filling this knowledge gap, the findings of study are also of practical importance, namely that care has to be taken before considering the mixed use of fungal parasites for insect pest control.

Supplementary Materials: The following are available online at https://www.mdpi.com/article/10 .3390/jof7050385/s1, Figure S1: Pairing growth of fungi on PDA for different times; Figure S2: Insect survivals; Figure S3: Biased mycosis; Figure S4: Microscopic examination of the time-scale growth of the co-inoculated RFP-Bb and GFP-Mr (1:1) in SDB for different time; Figure S5: Survival of the wax moth larvae after infections with divergent fungal strains. Table S1: Statistical comparison of the median lethal time $\left(\mathrm{LT}_{50}\right)$ between $\mathrm{Bb}$ and $\mathrm{Mr}$ after the topical infection assays against the last instar wax moth larvae; Table S2: Statistical comparison of the median lethal time $\left(\mathrm{LT}_{50}\right)$ between $\mathrm{Bb}$ and $\mathrm{Mr}$ after the injection assays against the last instar wax moth larvae; Table S3: Statistical comparison of the median lethal time $\left(\mathrm{LT}_{50}\right)$ between $\mathrm{Bb}$ and $\mathrm{Mr}$ after the topical infection assays against the female adults of fruit flies; Table S4: Statistical comparison of the median lethal time $\left(\mathrm{LT}_{50}\right)$ between $\mathrm{Bb}$ and $\mathrm{Mr}$ after the topical infection assays against the last instar mealworm larvae; Table S5: Statistical comparison of the median lethal time $\left(\mathrm{LT}_{50}\right)$ between two strains of M. robertsii after the topical infection assays against the last instar wax moth larvae; Statistical comparison of the median lethal time $\left(\mathrm{LT}_{50}\right)$ between two strains of $M$. robertsii after the injection assays against the last instar wax moth larvae; Table S7: Statistical comparison of the median lethal time $\left(\mathrm{LT}_{50}\right)$ between two strains of B. bassiana after the topical infection assays against the last instar wax moth larvae; Statistical comparison of the median lethal time $\left(\mathrm{LT}_{50}\right)$ between two strains of $M$. robertsii after the injection assays against the last instar wax moth larvae.

Author Contributions: Conceptualization, C.W.; methodology, S.L., W.Y. and S.C.; validation, S.L. and C.W.; formal analysis, C.W.; investigation, S.L., W.Y. and S.C.; data curation, C.W.; writingreview and editing, C.W.; supervision, C.W.; project administration, C.W.; funding acquisition, C.W. All authors have read and agreed to the published version of the manuscript.

Funding: This work was supported by the National Natural Science Foundation of China (No. 32021001) and the Chinese Academy of Sciences (No. QYZDJ-SSW-SMC028).

Institutional Review Board Statement: Not applicable.

Informed Consent Statement: Not applicable.

Data Availability Statement: Not applicable.

Conflicts of Interest: The authors declare no conflict of interest. The funders had no role in the design of the study; in the collection, analyses, or interpretation of data; in the writing of the manuscript; or in the decision to publish the results.

\section{References}

1. Stork, N.E. How many species of insects and other terrestrial arthropods are there on earth? Annu. Rev. Entomol. 2018, 63, 31-45. [CrossRef] [PubMed]

2. Mora, C.; Tittensor, D.P.; Adl, S.; Simpson, A.G.; Worm, B. How many species are there on Earth and in the ocean? PLoS Biol. 2011, 9, e1001127. [CrossRef] [PubMed]

3. Lovett, B.; St Leger, R.J. The insect pathogens. Microbiol. Spectr. 2017, 5, FUNK-0001-2016.

4. St Leger, R.J.; Wang, J.B. Metarhizium: Jack of all trades, master of many. Open Biol. 2020, 10, 200307. [CrossRef] [PubMed]

5. Steinwender, B.M.; Enkerli, J.; Widmer, F.; Eilenberg, J.; Kristensen, H.L.; Bidochka, M.J.; Meyling, N.V. Root isolations of Metarhizium spp. from crops reflect diversity in the soil and indicate no plant specificity. J. Invertebr. Pathol. 2015, 132, 142-148. [CrossRef]

6. Meyling, N.V.; Eilenberg, J. Ecology of the entomopathogenic fungi Beauveria bassiana and Metarhizium anisopliae in temperate agroecosystems: Potential for conservation biological control. Biol. Control 2007, 43, 145-155. [CrossRef]

7. Mei, L.J.; Chen, M.; Shang, Y.; Tang, G.; Tao, Y.; Zeng, L.; Huang, B.; Li, Z.; Zhan, S.; Wang, C.S. Population genomics and evolution of a fungal pathogen after releasing exotic strains to control insect pests for 20 years. ISME J. 2020, 14, 1422-1434 [CrossRef]

8. Hajek, A.E.; St Leger, R.J. Interactions between Fungal Pathogens and Insect Hosts. Annu. Rev. Entomol. 1994, 39, 293-322. [CrossRef]

9. Wang, C.; Shah, F.A.; Patel, N.; Li, Z.Z.; Butt, T.M. Molecular investigation on strain genetic relatedness and population structure of Beauveria bassiana. Environ. Microbiol. 2003, 5, 908-915. [CrossRef] 
10. Clifton, E.H.; Castrillo, L.A.; Gryganskyi, A.; Hajek, A.E. A pair of native fungal pathogens drives decline of a new invasive herbivore. Proc. Natl. Acad. Sci. USA 2019, 116, 9178-9180. [CrossRef]

11. Bremermann, H.J.; Thieme, H.R. A competitive exclusion principle for pathogen virulence. J. Math. Biol. 1989, 27, 179-190. [CrossRef]

12. Zheng, X.D.; Deng, L.L.; Qiang, W.Y.; Cressman, R.; Tao, Y. Limiting similarity of competitive species and demographic stochasticity. Phys. Rev. E 2017, 95, 042404. [CrossRef] [PubMed]

13. Smith, G.R.; Steidinger, B.S.; Bruns, T.D.; Peay, K.G. Competition-colonization tradeoffs structure fungal diversity. ISME J. 2018, 12, 1758-1767. [CrossRef] [PubMed]

14. Harbison, C.W.; Bush, S.E.; Malenke, J.R.; Clayton, D.H. Comparative transmission dynamics of competing parasite species. Ecology 2008, 89, 3186-3194. [CrossRef] [PubMed]

15. Chesson, P. Mechanisms of maintenance of species diversity. Annu. Rev. Ecol. Syst. 2000, 31, 343-366. [CrossRef]

16. Wang, C.S.; Feng, M.G. Advances in fundamental and applied studies in China of fungal biocontrol agents for use against arthropod pests. Biol. Control 2014, 68, 129-135. [CrossRef]

17. de Faria, M.R.; Wraight, S.P. Mycoinsecticides and mycoacaricides: A comprehensive list with worldwide coverage and international classification of formulation types. Biol. Control 2007, 43, 237-256. [CrossRef]

18. Uma Maheswara Rao, C.; Uma Devi, K.; Akbar Ali Khan, P. Effect of combination treatment with entomopathogenic fungi Beauveria bassiana and Nomuraea rileyi (Hypocreales) on Spodoptera litura (Lepidoptera: Noctuidaeae). Biocontrol Sci. Technol. 2007, 16, 221-232. [CrossRef]

19. Seid, A.M.; Fredensborg, B.L.; Steinwender, B.M.; Meyling, N.V. Temperature-dependent germination, growth and co-infection of Beauveria spp. isolates from different climatic regions. Biocontrol Sci Techn. 2019, 29, 411-426. [CrossRef]

20. Inglis, G.D.; Johnson, D.L.; Cheng, K.J.; Goettel, M.S. Use of pathogen combinations to overcome the constraints of temperature on entomopathogenic hyphomycetes against grasshoppers. Biol. Control 1997, 8, 143-152. [CrossRef]

21. Wang, C.; Fan, M.; Li, Z.Z.; Butt, T.M. Molecular monitoring and evaluation of the application of the insect-pathogenic fungus Beauveria bassiana in southeast China. J. Appl. Microbiol. 2004, 96, 861-870. [CrossRef]

22. Wang, C.S.; Wang, S.B. Insect pathogenic fungi: Genomics, molecular interactions, and genetic improvements. Annu. Rev. Entomol. 2017, 62, 73-90. [CrossRef]

23. Valero-Jimenez, C.A.; Faino, L.; Spring In't Veld, D.; Smit, S.; Zwaan, B.J.; van Kan, J.A. Comparative genomics of Beauveria bassiana: Uncovering signatures of virulence against mosquitoes. BMC Genom. 2016, 17, 986. [CrossRef] [PubMed]

24. Hu, X.; Xiao, G.; Zheng, P.; Shang, Y.; Su, Y.; Zhang, X.; Liu, X.; Zhan, S.; St Leger, R.J.; Wang, C. Trajectory and genomic determinants of fungal-pathogen speciation and host adaptation. Proc. Natl. Acad. Sci. USA 2014, 111, 16796-16801. [CrossRef] [PubMed]

25. Cen, K.; Li, B.; Lu, Y.Z.; Zhang, S.W.; Wang, C.S. Divergent LysM effectors contribute to the virulence of Beauveria bassiana by evasion of insect immune defenses. PLoS Pathog. 2017, 13, e1006604. [CrossRef]

26. Fang, W.; Pei, Y.; Bidochka, M.J. Transformation of Metarhizium anisopliae mediated by Agrobacterium tumefaciens. Can. J. Microbiol. 2006, 52, 623-626. [CrossRef] [PubMed]

27. Gottar, M.; Gobert, V.; Matskevich, A.; Reichhart, J.; Wang, C.; Butt, T.; BeIvin, M.; Hoffmann, J.; Ferrandon, D. Dual detection of fungal infections in Drosophila via recognition of glucans and sensing of virulence factors. Cell 2006, 127, 1425-1437. [CrossRef] [PubMed]

28. Tang, G.R.; Shang, Y.F.; Li, S.Q.; Wang, C.S. MrHex1 is required for Woronin body formation, fungal development and virulence in Metarhizium robertsii. J. Fungi 2020, 6, 172. [CrossRef] [PubMed]

29. Huang, A.; Lu, M.; Ling, E.; Li, P.; Wang, C.S. A M35 family metalloprotease is required for fungal virulence against insects by inactivating host prophenoloxidases and beyond. Virulence 2020, 11, 222-237. [CrossRef]

30. Shang, J.M.; Shang, Y.F.; Tang, G.R.; Wang, C.S. Identification of a key G-protein coupled receptor in mediating appressorium formation and fungal virulence against insects. Sci. China Life Sci. 2021, 64, 466-477.

31. Chen, Y.X.; Li, B.; Cen, K.; Lu, Y.Z.; Zhang, S.W.; Wang, C.S. Diverse effect of phosphatidylcholine biosynthetic genes on phospholipid homeostasis, cell autophagy and fungal developments in Metarhizium robertsii. Environ. Microbiol. 2018, 20, 293-304. [CrossRef] [PubMed]

32. Wang, C.S.; St Leger, R.J. The Metarhizium anisopliae perilipin homolog MPL1 regulates lipid metabolism, appressorial turgor pressure, and virulence. J. Biol. Chem. 2007, 282, 21110-21115. [CrossRef] [PubMed]

33. Alizon, S.; de Roode, J.C.; Michalakis, Y. Multiple infections and the evolution of virulence. Ecol. Lett. 2013, 16, 556-567. [CrossRef] [PubMed]

34. López-Villavicencio, M.; Jonot, O.; Coantic, A.; Hood, M.E.; Enjalbert, J.; Giraud, T. Multiple infections by the anther smut pathogen are frequent and involve related strains. PLoS Pathog. 2007, 3, e176. [CrossRef] [PubMed]

35. Susi, H.; Barres, B.; Vale, P.F.; Laine, A.L. Co-infection alters population dynamics of infectious disease. Nat. Commun. 2015, 6, 5975. [CrossRef] [PubMed]

36. Abbate, J.L.; Gladieux, P.; Hood, M.E.; de Vienne, D.M.; Antonovics, J.; Snirc, A.; Giraud, T. Co-occurrence among three divergent plant-castrating fungi in the same Silene host species. Mol. Ecol. 2018, 27, 3357-3370. [CrossRef] [PubMed]

37. Pauli, G.; Moura Mascarin, G.; Eilenberg, J.; Delalibera Junior, I. Within-host competition between two entomopathogenic fungi and a granulovirus in Diatraea saccharalis (Lepidoptera: Crambidae). Insects 2018, 9, 64. [CrossRef] [PubMed] 
38. Wang, C.; Li, Z.; Butt, T. Molecular studies of co-formulated strains of the entomopathogenic fungus, Beauveria bassiana. J. Invertebr. Pathol. 2002, 80, 29-34. [CrossRef]

39. Adler, P.B.; Fajardo, A.; Kleinhesselink, A.R.; Kraft, N.J. Trait-based tests of coexistence mechanisms. Ecol. Lett. 2013, 16, 1294-1306. [CrossRef]

40. Meyling, N.V.; Lubeck, M.; Buckley, E.P.; Eilenberg, J.; Rehner, S.A. Community composition, host range and genetic structure of the fungal entomopathogen Beauveria in adjoining agricultural and seminatural habitats. Mol. Ecol. 2009, 18, 1282-1293. [CrossRef]

41. Ramos, Y.; Portal, O.; Lysoe, E.; Meyling, N.V.; Klingen, I. Diversity and abundance of Beauveria bassiana in soils, stink bugs and plant tissues of common bean from organic and conventional fields. J. Invertebr. Pathol. 2017, 150, 114-120. [CrossRef] [PubMed]

42. Shang, Y.F.; Xiao, G.H.; Zheng, P.; Cen, K.; Zhan, S.; Wang, C.S. Divergent and convergent evolution of fungal pathogenicity. Genome Biol. Evol. 2016, 8, 1374-1387. [CrossRef]

43. Lee, M.R.; Powell, J.R.; Oberle, B.; Cornwell, W.K.; Lyons, M.; Rigg, J.L.; Zanne, A.E. Good neighbors aplenty: Fungal endophytes rarely exhibit competitive exclusion patterns across a span of woody habitats. Ecology 2019, 100, e02790. [CrossRef]

44. Kennedy, P. Ectomycorrhizal fungi and interspecific competition: Species interactions, community structure, coexistence mechanisms, and future research directions. New Phytol. 2010, 187, 895-910. [CrossRef] [PubMed]

45. Bennett, A.E.; Bever, J.D. Trade-offs between arbuscular mycorrhizal fungal competitive ability and host growth promotion in Plantago lanceolata. Oecologia 2009, 160, 807-816. [CrossRef]

46. Wang, S.; O'Brien, T.R.; Pava-Ripoll, M.; St Leger, R.J. Local adaptation of an introduced transgenic insect fungal pathogen due to new beneficial mutations. Proc. Natl. Acad. Sci. USA 2011, 108, 20449-20454. [CrossRef] [PubMed]

47. Grainger, T.N.; Letten, A.D.; Gilbert, B.; Fukami, T. Applying modern coexistence theory to priority effects. Proc. Natl. Acad. Sci. USA 2019, 116, 6205-6210. [CrossRef]

48. Levine, J.M.; HilleRisLambers, J. The importance of niches for the maintenance of species diversity. Nature 2009, 461, 254-257. [CrossRef]

49. Araujo, J.P.M.; Evans, H.C.; Kepler, R.; Hughes, D.P. Zombie-ant fungi across continents: 15 new species and new combinations within Ophiocordyceps. I. Myrmecophilous hirsutelloid species. Stud. Mycol. 2018, 90, 119-160. [CrossRef]

50. Thomas, M.B.; Watson, E.L.; Valverde-Garcia, P. Mixed infections and insect-pathogen interactions. Ecol. Lett. 2003, 6, 183-188. [CrossRef]

51. Ulrich, Y.; Schmid-Hempel, P. Host modulation of parasite competition in multiple infections. Proc. Biol. Sci. 2012, 279 , 2982-2989. [CrossRef] [PubMed]

52. de Roode, J.C.; Culleton, R.; Cheesman, S.J.; Carter, R.; Read, A.F. Host heterogeneity is a determinant of competitive exclusion or coexistence in genetically diverse malaria infections. Proc. Biol. Sci. 2004, 271, 1073-1080. [CrossRef] [PubMed]

53. Duwadi, D.; Shrestha, A.; Yilma, B.; Kozlovski, I.; Sa-Eed, M.; Dahal, N.; Jukosky, J. Identification and screening of potent antimicrobial peptides in arthropod genomes. Peptides 2018, 103, 26-30. [CrossRef] [PubMed]

54. Hughes, W.O.; Boomsma, J.J. Let your enemy do the work: Within-host interactions between two fungal parasites of leaf-cutting ants. Proc. Biol. Sci. 2004, 271, S104-S106. [CrossRef]

55. Chouvenc, T.; Efstathion, C.A.; Elliott, M.L.; Su, N.-Y. Resource competition between two fungal parasites in subterranean termites. Naturwissenschaften 2012, 99, 949-958. [CrossRef] [PubMed]

56. Milutinovic, B.; Stock, M.; Grasse, A.V.; Naderlinger, E.; Hilbe, C.; Cremer, S. Social immunity modulates competition between coinfecting pathogens. Ecol. Lett. 2020, 23, 565-574. [CrossRef]

57. Maistrou, S.; Natsopoulou, M.E.; Jensen, A.B.; Meyling, N.V. Virulence traits within a community of the fungal entomopathogen Beauveria: Associations with abundance and distribution. Fungal Ecol. 2020, 48, 100992. [CrossRef]

58. Klinger, E.G.; Vojvodic, S.; DeGrandi-Hoffman, G.; Welker, D.L.; James, R.R. Mixed infections reveal virulence differences between host-specific bee pathogens. J. Invertebr. Pathol. 2015, 129, 28-35. [CrossRef]

59. Behie, S.W.; Zelisko, P.M.; Bidochka, M.J. Endophytic insect-parasitic fungi translocate nitrogen directly from insects to plants. Science 2012, 336, 1576-1577. [CrossRef]

60. Behie, S.W.; Moreira, C.C.; Sementchoukova, I.; Barelli, L.; Zelisko, P.M.; Bidochka, M.J. Carbon translocation from a plant to an insect-pathogenic endophytic fungus. Nat. Commun. 2017, 8, 14245. [CrossRef]

61. Mayfield, M.M.; Levine, J.M. Opposing effects of competitive exclusion on the phylogenetic structure of communities. Ecol. Lett. 2010, 13, 1085-1093. [CrossRef] [PubMed]

62. Potts, J.R.; Petrovskii, S.V. Fortune favours the brave: Movement responses shape demographic dynamics in strongly competing populations. J. Theor. Biol. 2017, 420, 190-199. [CrossRef]

63. Zheng, P.; Xia, Y.; Zhang, S.; Wang, C. Genetics of Cordyceps and related fungi. Appl. Microbiol. Biotechnol. 2013, 97, $2797-2804$. [CrossRef] [PubMed]

64. Saupe, S.J. Molecular genetics of heterokaryon incompatibility in filamentous ascomycetes. Microbiol. Mol. Biol. Rev. 2000, 64, 489-502. [CrossRef] [PubMed] 